\title{
Comparative Latent State-Trait Analysis of Satisfaction with Life Measures: The Steen Happiness Index and the Satisfaction with Life Scale
}

\author{
Lukasz D. Kaczmarek • Aleksandra Bujacz • Michael Eid
}

Published online: 19 March 2014

(C) The Author(s) 2014. This article is published with open access at Springerlink.com

\begin{abstract}
The variance in satisfaction with life can be broken down into trait- and state-like components. We ran tests to determine if a new scale for the measurement of satisfaction with life, the Steen Happiness Index (SHI), was more sensitive to situational changes than the Satisfaction with Life Scale (SWLS), which is currently used as a gold standard, with wellestablished state-trait characteristics. The study consisted of 292 young adults aged 18-35, who were recruited and interviewed three times with 5-month intervals at their places of residence. They completed a set of questionnaires involving the SHI and the SWLS. A latent autoregressive state-trait model showed an adequate fit, $\chi^{2}(56)=81.35, p=.02$, $\chi^{2} / d f=1.45, \mathrm{RMSEA}=.06, \mathrm{CFI}=.98, \mathrm{SRMR}=.06$. The results indicated that the two scales are strongly correlated on the trait level $(r=.98)$ and on the occasion-specific level (between $r=.53$ and $r=.65$ ) variables. For both scales, stable and occasion-specific influences determine inter-individual differences. For both scales, it is not possible to predict half of the variance by either traits or states measured earlier in time.
\end{abstract}

Keywords Satisfaction with life $\cdot$ Latent state-trait models $\cdot$ Multistate-multitrait models

\section{Introduction}

Several instruments have already been developed to measure satisfaction with life (Cummins et al. 2003; Diener et al. 1985). Choosing one of them should depend on how their psychometric properties fit the aim of a study. Some research problems within the field of happiness studies require measures relatively immune to influences of a particular

L. D. Kaczmarek $(\varangle) \cdot$ A. Bujacz

Institute of Psychology, Adam Mickiewicz University, 89 Szamarzewskiego Street, 60-568 Poznan, Poland

e-mail: Lkacz@amu.edu.pl

M. Eid

Free University of Berlin, Berlin, Germany 
moment in a person's life. For instance, the utility of indicators used in national surveys depends on the measures that do not account for the unique characteristics of the specific day of measurement (Campbell et al. 1976). Another group of researchers aims at estimating influences of meaningful situational factors, such as becoming a spouse or a parent (Kohler et al. 2005), or more transient ones, such as the initiation of interventions meant to temporarily boost satisfaction with life (Seligman et al. 2005b). In the latter case, the validity of data can depend on the sensitivity of measurement instruments to account for occasion-specific variance. Testing such sensitivity is possible with latent state-trait (LST) models (Steyer et al. 1999). Yet, only the Satisfaction with Life Scale (SWLS) (Diener et al. 1985) has already received a LST characteristic showing that only $16 \%$ of its score depends on situational influences (Eid and Diener 2004). In the current study, we tested whether a new scale of satisfaction with life, namely the Steen Happiness Index (SHI; Seligman et al. 2005a, b), is a better trap for occasion-specificity. This analysis addresses the underexplored arena of the dynamics of well-being (Brockman and Delhey 2010).

\subsection{Partitioning Dynamics of Well-Being}

There is theoretical and empirical support for distinguishing between short-term and longterm aspects of satisfaction with life. A study involving several thousands of twins indicated that genetic influences are the single major factor explaining 44-52\% of the variance in subjective well-being (Lykken and Tellegen 1996). Other factors seemed to have a negligible effect in that study when controlling for genetically determined happiness level. Circumstances accounted for an unexpectedly small amount of variance, for example, less than $2 \%$ for educational attainment, socio-economic status, or income, and less than $1 \%$ for marital status (Lykken and Tellegen 1996). Even intense social turmoil, such as a national economic downfall, can have very little to no impact on satisfaction with life for many individuals (Gudmundsdottir 2013).

There are several theories that explain the stability of well-being, for example, the adaptation-level theory of well-being (Brickman and Campbell 1971), personality theory of subjective well-being (Costa and McCrae 1980), dynamic equilibrium theory (Headey and Wearing 1989), multiple discrepancies theory (Michalos 1985), and homeostatic theory (Cummins 1995). However, the claim that the happiness set-point does not evolve has also been a subject of criticism (Diener et al. 2006; Headey 2008, 2010). For instance, unemployment can change the individual set-point for satisfaction with life (Lucas et al. 2004). Moreover, personality traits change over time and such changes can consistently affect life satisfaction (Boyce et al. 2013; Scollon and Diener 2006).

Another group of theories and research suggests that happiness has high temporal instability (Veenhoven 1994) and depends strongly on intentional activity (Lyubomirsky et al. 2005; Sheldon and Lyubomirsky 2006). Several studies have documented that theorybased cognitive or interpersonal exercises can temporarily boost satisfaction with life (Fordyce 1977, 1983; Lyubomirsky et al. 2011; Odou and Vella-Brodrick 2013; Mongrain and Anselmo-Matthews 2012; Seligman et al. 2005b; Sin and Lyubomirsky 2009). The probability of detecting such changes depends on the ability of a measurement tool to account for the occasion-specific variance.

\subsection{Trait-State Conceptualization of Well-Being}

The problem of stability and changeability in well-being indicators has been addressed with several methods in the literature. For instance, well-being as an outcome can be 
correlated with subjective and objective markers of change in circumstances (Atkinson 1982; Michalos and Kahlke 2010). Another approach is derived from LST statistical models that were developed specifically to address the issues of change and stability in assessment (Steyer et al. 1999; Eid and Diener 2004).

The LST models divide variance into the effects of a stable trait variable and an occasion-specific variable. These components of overall variance in the measurement can be separated when measurements using the same scale are taken on several occasions. These models separate the variability due to measurement error from the reliable variability due to occasion. Therefore, the LST models avoid the problem of overestimation of the true instability. This gives an advantage to the LST approach over analyses performed on observed variables that do not control for the measurement error. Trait- and occasionspecific variance determine the overall reliability of an instrument. Additionally, each scale can be divided into halves to test the reliability of the occasion-specific component. LST theory allows for building models that can address several psychometric problems. Notably, they can be combined into multistate-multitrait models and used to estimate relationships between different measures. It is then possible to test whether situational factors influence occasion-specific components of particular measures (Eid 1996).

The SWLS has been employed in previous studies concerned with stability and change of measurements (Eid and Diener 2004). Thus, it can serve as a reference point in the validation of other well-being scales. Satisfaction with life represents the cognitive component of subjective well-being. It is manifested in global positive judgments about life (Diener et al. 1985). Based on a multistate-multitrait model with three measurements and monthly intervals, Eid and Diener (2004) found that $12-16 \%$ of the variance in satisfaction with life was due to occasion-specific influences, whereas $74-83 \%$ of the variance was determined by stable trait differences. Similar results were observed by Lucas and Donnellan (2012), who tested single-item life satisfaction indicators using the Stable Trait, Autoregressive Trait, State model (Kenny and Zautra 1995). They reported shared state (occasion-specific) variance from 5 to $13 \%$, trait variance decomposed into stable trait (26-38\%), and autoregressive trait from 24 to $36 \%$. The results of these studies suggest that the contribution of situational factors to the measurement of satisfaction with life is several times smaller than the contribution of stable components (e.g., set-point). The amount of occasion-specific variance for the SWLS was much lower than the proposed $50 \%$ attributable to circumstances and intentional activity. (Lyubomirsky et al. 2005). The SHI (Seligman et al. 2005a, b) might allow for a more precise measurement of occasionspecific aspects of satisfaction with life.

\subsection{Towards Latent State-Trait Analysis of the Steen Happiness Index}

Tracy Steen and colleagues have developed the SHI to measure satisfaction with emotional life, engagement, and meaning in life (Seligman et al. 2005a, b). The primary purpose of this scale was to measure changes in levels of satisfaction caused by positive psychology interventions (Seligman et al. 2005b; Mongrain et al. 2011; Mongrain and AnselmoMatthews 2012). The scale was modeled after the Beck Depression Inventory (Beck et al. 1961). It requires participants to read a series of statements and pick the one that described them best during the past week. The convergent validity of the scale (Seligman et al. 2005b) was indicated by high correlations with other indicators of happiness, such as the General Happiness Scale (Lyubomirsky and Lepper 1999) and the Happiness Scale (Fordyce 1977). 
In general, people rate themselves as reasonably happy (Cummins 1995; Myers and Diener 1996). Consequently, scores on most well-being scales are negatively distributed. The SHI was expected to be less skewed toward higher scores because it contains only one negative and one neutral option, and three positive response possibilities ranging from mild to extreme among each group of statements. This set of response choices led to a more bell-shaped distribution (Seligman et al. 2005b). Thus, the SHI might be more suitable for differentiating higher ranges of satisfaction with life where meaningful short-term oscillations might occur.

In the current study, we expected that the amount of occasion-specific variance would be higher for the SHI than for the SWLS due to the different temporal reference points suggested in the instructions for both scales. We also expected that there would be a high correlation between the measurement of traits with the SHI and the SWLS as both indicate satisfaction with life.

\section{Method}

\subsection{Participants}

This study involved 292 participants representative of young adults in terms of place of residence, education, and gender. Of the participants, 146 completed three measurements required for the LST analysis. Those who dropped out from the sample did not differ from those who remained in respect to their SWLS baseline score, SHI baseline score, age, educational attainment, population center size, or gender, all $t \mathrm{~s}<1.94$, all $p \mathrm{~s}>.05$. Gender of the participants did not predict the dropout either, $\chi^{2}(2)=1.56, p>.05$.

The inclusion criterion was being aged between 18 and 35 years. The first measurement (T1) was taken in August, the second (T2) in January, and the last (T3) in June. Data collection was performed by professional pollsters from a certified firm that specialized in public opinion polls. The surveys were taken face-to-face at the place of the respondent's residence. National census data were used to achieve the sample representativeness for the young adult population. Until the quota for a specific population center size (such as, village, town under 50,000) was achieved, a new population center of a particular size in Poland, and an address within this population center, was selected at random. The pollsters visited this location and conducted the survey if they found a person matching the gender and educational attainment needed for the quota who volunteered to participate in the research at that location. If none of the residents at this address met these criteria, the pollsters moved to the next address. In sum, data was collected in 57 different population centers that ranged from villages to cities with populations over 500,000 (Table 1). Missing data were input using the expectation-maximization algorithm in SPSS 21. Participants received detailed information about the study and their rights, including the right to withdraw from the study at any point. Written informed consent was obtained from each of them. This study was approved by the institution's Research Ethics Committee.

\subsection{Measures}

The Steen Happiness Index (Seligman et al. 2005b): This scale contains 20 items and requires participants to read a series of statements and pick the one that best describes them during the past week. Response choices range from a negative ("Most of the time I am bored") to an extremely positive ("Most of the time I am fascinated by what I am doing"). 
Table 1 Demographic characteristics of the participants

\begin{tabular}{|c|c|c|c|}
\hline & \multicolumn{3}{|l|}{ Wave } \\
\hline & $\mathrm{T} 1(N=292)$ & $\mathrm{T} 2(N=253)$ & $\mathrm{T} 3(N=146)$ \\
\hline Age & $26.34 \pm 5.5$ & $26.12 \pm 5.6$ & $27.7 \pm 5.43$ \\
\hline \multicolumn{4}{|l|}{ Gender } \\
\hline Female & $142(47.5)$ & $125(49.2)$ & $75(51.4)$ \\
\hline Male & $149(50.2)$ & $128(50.4)$ & $71(48.6)$ \\
\hline \multicolumn{4}{|c|}{ Size of population center } \\
\hline Village & $99(33.1)$ & $88(34.6)$ & $63(43.2)$ \\
\hline$<50,000$ & $64(21.4)$ & $51(20.1)$ & 32 (21.9) \\
\hline $50,000-200,000$ & $57(19.1)$ & 45 (17.7) & $15(10.3)$ \\
\hline $200,000-500,000$ & $27(9.0)$ & $23(9.1)$ & $10(6.8)$ \\
\hline$>500,000$ & $41(13.7)$ & $40(15.7)$ & $25(17.1)$ \\
\hline \multicolumn{4}{|l|}{ Occupation } \\
\hline Learning & $32(10.7)$ & $26(10.2)$ & $10(6.8)$ \\
\hline Student & $38(12.7)$ & $32(12.6)$ & $16(11.0)$ \\
\hline Employed & $165(55.2)$ & $141(55.0)$ & $90(61.6)$ \\
\hline Pensioner & $2(.7)$ & $3(1.2)$ & $0(0)$ \\
\hline Unemployed & $23(7.7)$ & $25(9.8)$ & $13(8.9)$ \\
\hline Houskeeping & $26(8.7)$ & $13(5.1)$ & $16(11.0)$ \\
\hline Other & $3(1.0)$ & $4(1.6)$ & $1(1)$ \\
\hline \multicolumn{4}{|l|}{ Education } \\
\hline Elementary & $28(9.4)$ & $23(9.1)$ & $11(7.5)$ \\
\hline Vocational & $56(18.7)$ & $39(15.4)$ & $26(17.8)$ \\
\hline Vocational middle & $53(17.7)$ & 48 (18.9) & $26(17.8)$ \\
\hline Secondary & $44(14.7)$ & $45(17.75)$ & $28(19.2)$ \\
\hline Post secondary & $9(3.0)$ & $10(3.9)$ & $5(3.4)$ \\
\hline Higher incomplete & $11(3.7)$ & $15(5.9)$ & $8(5.5)$ \\
\hline Higher & $89(29.8)$ & $68(26.8)$ & $41(28.1)$ \\
\hline \multicolumn{4}{|l|}{ Interpersonal status } \\
\hline Married & $113(37.8)$ & $94(37.0)$ & $65(44.5)$ \\
\hline Engaged & $10(3.3)$ & $10(3.9)$ & $5(3.4)$ \\
\hline Cohabitation & $27(9.0)$ & $19(7.5)$ & $9(6.2)$ \\
\hline Dating & $28(9.4)$ & $25(9.85)$ & $7(4.8)$ \\
\hline Single & $111(37.1)$ & $99(39.0)$ & $57(39.0)$ \\
\hline Other & $2(.7)$ & $3(1.25)$ & $3(2.1)$ \\
\hline
\end{tabular}

Values in parentheses represent $\%$

Each response is assigned a value ranging from 1 to 5 , with 5 indicating the most positive response. The items cover the areas of pleasure ("My life is filled with pleasure"), engagement ("Time passes so quickly during all of my activities that I do not even notice it") and meaning ("I have a very clear idea about my purpose in life"). The total score is the sum of each individual item. Descriptive statistics and reliabilities of this and the remaining scales are presented in Table 2. 
Table 2 Descriptive statistics and correlations $(N=146)$

\begin{tabular}{lllllllllllll}
\hline & 1 & 2 & 3 & 4 & 5 & 6 & 7 & 8 & 9 & 10 & 11 & $M(S D)$ \\
\hline 1. T1 SHI 1 half & - & & & & & & & & & & & $3.03(.54)$ \\
2. T1 SHI 2 half & .85 & - & & & & & & & & & & $3.15(.54)$ \\
3. T2 SHI 1 half & .53 & .48 & - & & & & & & & & & $3.01(.58)$ \\
4. T2 SHI 2 half & .55 & .54 & .86 & - & & & & & & & & $3.22(.55)$ \\
5. T3 SHI 1 half & .48 & .46 & .61 & .62 & - & & & & & & & $3.13(.52)$ \\
6. T3 SHI 2 half & .47 & .45 & .58 & .64 & .86 & - & & & & & & $3.26(.53)$ \\
7. T1 SWLS 1 half & .63 & .56 & .45 & .48 & .44 & .46 & - & & & & & $4.32(1.17)$ \\
8. T1 SWLS 2 half & .51 & .44 & .38 & .40 & .45 & .42 & .83 & - & & & & $4.01(1.19)$ \\
9. T2 SWLS 1 half & .44 & .37 & .67 & .64 & .43 & .45 & .60 & .56 & - & & & $4.40(1.23)$ \\
10. T2 SWLS 2 half & .34 & .25 & .57 & .55 & .36 & .37 & .56 & .58 & .83 & - & & $4.31(1.19)$ \\
11. T3 SWLS 1 half & .46 & .39 & .43 & .47 & .64 & .62 & .54 & .46 & .61 & .58 & - & $4.43(1.14)$ \\
12. T3 SWLS 2 half & .45 & .39 & .46 & .49 & .60 & .55 & .46 & .45 & .58 & .60 & .80 & $4.34(1.06)$ \\
\hline
\end{tabular}

SHI Steen Happiness Index-PL, SWLS Satisfaction with Life Scale

$* p<.05 ; * *<<.05$

The Satisfaction with Life Scale (Diener et al. 1985): The five items on this scale measured global cognitive judgments of one's life. One example is "The conditions of my life are excellent." The answering scale ranges from 1 (strongly disagree) to 7 (strongly agree).

Demographic variables: A generic questionnaire was used to obtain basic demographic characteristics. The response categories are presented in Table 1.

\subsection{Data Analysis}

Calculations, using structural equation modeling, were based on the LST theory (Steyer et al. 1999). This allowed us to separate measurement error from variability that reflects systematic influences of situations and time. To separate measurement error from true state scores we split each measurement into two halves (even vs. odd items). Measurement invariance was introduced by fixing factor loadings and intercepts to be equal for each of the test halves across time.

Latent trait variables represented the stable component of all observed variables, nonspecific to the occasion of measurement. Latent occasion-specific variables accounted for the deviations of the time-specific states from the stable level of life satisfaction. In line with the theory of LST models, we assumed that latent traits were not correlated with occasion-specific variables and error variables (Eid 1996). Finally, we included autoregressive effects on the level of the occasion-specific variables in the model to estimate the amount of occasion-specific variance predicted by the preceding measurement (Eid et al. 2012).

To estimate the fluctuation of satisfaction over time we dissected the variance of observed measurement into three coefficients (Steyer et al. 1999; Geiser and Lockhart 2012). The reliability index (Rel) pertains to reliable sources of variance rather than the measurement error. The occasion specificity coefficient (OSpe) indicates to which degree the measurement reflects situational influences or interaction between a person and a 
situation. Lastly, the consistency coefficient (Con) informs the degree to which measurement is determined by stable person-specific effects. To account for the autoregressive effects, we calculated two coefficients. The unpredictability index (Upred) represents the true unpredictable fluctuations of the occasions of measurement that cannot be predicted, neither by the trait variable, nor by the autoregressive process (Eid et al. 2012). It represents the total amount of instability on the latent level. The counterpart of it is the predictability coefficient (Pred) that represents the amount of true state variance that is determined by the trait and the inertia of the autoregressive process.

The latent autoregressive state-trait model was extended to a multi-construct model (Eid and Diener 2004). One part of the model included the SHI, the other part the SWLS (Fig. 1). Correlations between latent, occasion-specific factors for the SHI and the SWLS were allowed at each measurement occasion.

All analyses were performed with Mplus 7.11 (Muthén and Muthén, 1998-2012), using the robust maximum likelihood estimation (MLR). A $\chi^{2}$-test CFI, RMSEA, and SRMR were applied for the evaluation, with the respective cut-off values as presented by Schweizer (2010).

\section{Results}

Descriptive statistics and correlations are presented in Table 2. The fit of the latent autoregressive state-trait model with strong measurement invariance (Fig. 1) to empirical data was satisfactory, $\chi^{2}(56)=81.35, p=.02, \chi^{2} / d f=1.45, \mathrm{RMSEA}=.06,90 \% \mathrm{CI}$ $[.02 ; .08], \mathrm{CFI}=.98, \mathrm{SRMR}=.06$. In this model, it was assumed that the loadings and intercepts do not change over time. This also implies that there is no mean change over time (Geiser et al. in press). In order to test, in a stronger way, the hypotheses of no mean changes, we compared the fit of the model with strong measurement with the fit of the model with weak measurement invariance (freely estimated intercepts). The model with weak measurement invariance did not fit the data better $\left[\chi^{2}(48)=70.61, p=.02\right.$; MLR- $\chi^{2}$-difference test; $\left.\chi^{2}(8)=10.83, p=.21\right]$. Variance components and reliability coefficients (Eid et al. 2012) for standardized solutions are presented in Table 3.

The reliability coefficients (Rel) ranged from .78 to .93 for the SHI, and from .78 to .92 for the SWLS (Table 3). Thus, the proportion of variance not due to measurement error was satisfactory for both scales. The estimated occasion-specificity coefficients ranged from .58 to .76 for the SHI and from .69 to .87 for the SWLS. Consequently, the consistency coefficients ranged from .24 to .43 for the SHI and from .14 to .35 for the SWLS. This suggests that life satisfaction scores were more related to occasion-specific influences than to the traits.

However, the unpredictability coefficients were much lower than the occasion-specificity coefficients ranging from .40 to .61 for SHI and from .38 to .61 for the SWLS. The predictability coefficients exceeded the consistency coefficients as they varied from .39 to .60 for the SHI, and from .39 to .62 for the SWLS. That means that, in sum, about half of the true variance of inter-individual differences in life satisfaction on an occasion of measurement is predictable by trait influence and autoregressive effects (inertia), whereas half of the variance is due to unique occasion-specific influences.

Furthermore, the standardized correlation of .98 indicated that the SHI and the SWLS latent trait variables were almost identical. The correlations between occasion-specific measures of the SHI and the SWLS on the level of occasion-specific variables and residuals were lower and ranged from .53 to .65 . 


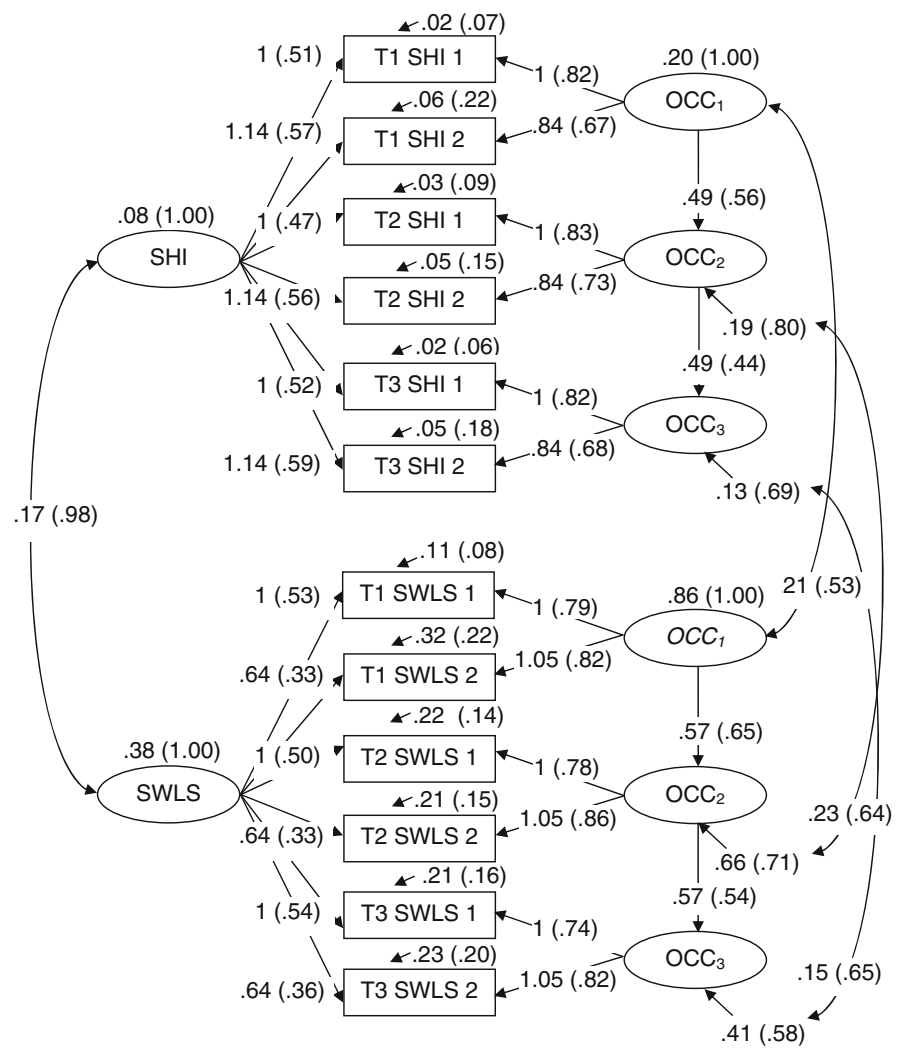

Fig. 1 Estimated parameters of the latent autoregressive state-trait model for three occasions of measurement. Reported are the unstandardized parameter estimates and standardized parameter estimates (in parentheses) according to the completely standardized solution. SHI: Steen Happiness Index; SWLS: Satisfaction with Life Scale; OCC $_{\mathrm{t}}$ : latent occasion-specific variables; T: consecutive times of measurement with 5-month intervals

\section{Discussion}

In this study, we applied a latent autoregressive state-trait model in order to analyze variability and change in the SHI and the SWLS. The results suggested that the SHI accounted for an amount of trait and state variance similar to that of the SWLS, used as the gold standard in the present study. The ratio of state to trait variance was in line with those models of well-being that assume the 50/50 split between the set-point and effects of situations (Lyubomirsky et al. 2005). Of note, separating the error variance minimized the risk of overestimation of true instability of the SHI scores. This finding adds to the discussion in the literature concerned with the psychological significance of the short-term fluctuations in well-being. More importantly, it contradicts the notion of situational inconsistency in well-being levels (Veenhoven 1994).

The correlations between the latent variables belonging to the different scales provided evidence for convergent validity of the SHI scale and the SWLS. As expected, the correlations were positive and strong. This indicates that the SHI and the SWLS measure very similar constructs. The SHI and the SWLS had similar amounts of variance attributable to 
Table 3 Estimated variance components for the latent autoregressive state-trait model $(N=146)$

\begin{tabular}{llllll}
\hline & Rel & OSpe & Con & Upred & Pred \\
\hline 1. T1 SHI 1 half & .93 & .72 & .28 & - & 1 \\
2. T1 SHI 2 half & .78 & .58 & .42 & - & 1 \\
3. T2 SHI 1 half & .91 & .76 & .24 & .61 & .39 \\
4. T2 SHI 2 half & .85 & .63 & .37 & .51 & .49 \\
5. T3 SHI 1 half & .94 & .71 & .29 & .49 & .51 \\
6. T3 SHI 2 half & .82 & .58 & .43 & .40 & .60 \\
7. T1 SWLS 1 half & .92 & .69 & .31 & - & 1 \\
8. T1 SWLS 2 half & .78 & .86 & .14 & - & 1 \\
9. T2 SWLS 1 half & .86 & .71 & .29 & .50 & .50 \\
10. T2 SWLS 2 half & .85 & .87 & .13 & .61 & .39 \\
11. T3 SWLS 1 half & .84 & .65 & .35 & .38 & .62 \\
12. T3 SWLS 2 half & .80 & .84 & .17 & .48 & .52 \\
\hline
\end{tabular}

Rel reliability, OSpe occasion-specificity, Con consistency, Upred unpredictability, Pred predictability, SHI Steen Happiness Index, SWLS Satisfaction with Life Scale

traits and occasion-specific influences. This seems to contradict our predictions that the SHI is more sensitive for occasion specificity than the SWLS. Although traits behind the SHI and the SWLS were almost perfectly correlated (.98), the correlations between the SHI and the SWLS's occasion-specificity on a particular occasion of measurement were moderate. As previously noted, occasion-specificity reflects variance left after controlling for the trait effects and the measurement error. Consequently, relatively lower correlations between the occasion-specific factors suggest that the SHI and the SWLS are sensitive to both similar and distinct situational influences, despite their common trait identity. This is a novel finding that has not been previously described in the literature concerned with satisfaction with life.

The following limitation should be considered when interpreting our findings. Despite the sample heterogeneity in respect to gender, educational attainment, occupational status, and size of population center, our sample was limited to young adults, i.e. 18-35 years old. Thus, further studies might test if these results apply also to other age cohorts.

In sum, our findings suggest that the measurements of satisfaction with life with the SHI are reliable and can be broken down into two theoretically justified components. One component is attributable to the stable trait of satisfaction. The second component represents occasion-specific influences. We built a latent autoregressive state-trait model that suggested that the SHI and the SWLS measured identical traits but distinct occasionspecific influences. Thus, for the purpose of the trait measurement, the SWLS might be preferred due to a much briefer form (fewer items and an easier response format). However, the SHI provides the opportunity to measure unique aspects of situational well-being. Further studies might examine what unique aspects of situations are measured by each of these scales.

Acknowledgments Project funded by the National Science Center, Poland (NN 1062912 39).

Open Access This article is distributed under the terms of the Creative Commons Attribution License which permits any use, distribution, and reproduction in any medium, provided the original author(s) and the source are credited. 


\section{References}

Atkinson, T. (1982). The stability and validity of quality of life measures. Social Indicators Research, 10, $113-132$.

Beck, A. T., Ward, C. H., Mendelson, M. N., Mock, J., \& Erbaugh, J. (1961). An inventory for measuring depression. Archives of General Psychiatry, 4, 561-571.

Boyce, C. J., Wood, A. M., \& Powdthavee, N. (2013). Is personality fixed? Personality changes as much as "variable" economic factors and more strongly predicts changes to life satisfaction. Social Indicators Research, 111, 287-305.

Brickman, P. D., \& Campbell, D. T. (1971). Hedonic relativism and planning the good society. In M. H. Appley (Ed.), Adaptation level theory. New York: Academic Press.

Brockman, H., \& Delhey, J. (2010). Introduction: The dynamics of happiness and the dynamics of happiness research. Social Indicators Research, 97, 1-5.

Campbell, A., Converse, P. E., \& Rodgers, W. L. (1976). The quality of American life. Perceptions, evaluations, and satisfactions. New York: Russell Sage Foundation.

Costa, P. T., \& McCrae, R. R. (1980). Influences of extraversion and neuroticism on subjective well-being. Journal of Personality and Social Psychology, 38, 668-678.

Cummins, R. A. (1995). On the trail of the gold standard for life satisfaction. Social Indicators Research, 35 , 179-200.

Cummins, R. A., Eckersley, R., Pallant, J., Van Vugt, J., \& Misajon, R. (2003). Developing a national index of subjective wellbeing: The Australian Unity Wellbeing Index. Social Indicators Research, 64(2), 159-190.

Diener, E., Emmons, R. A., Larsen, R. J., \& Griffin, S. (1985). The satisfaction with life scale. Journal of Personality Assessment, 49, 71-75.

Dierner, E., Lucas, R. E., \& Scollon, C. N. (2006). Beyond the hedonic treadmill. Revising the adaptation theory of well-being. American Psychologist, 61, 305-314.

Eid, M. (1996). Longitudinal confirmatory factor analysis for polytomous item responses. Model definition and model selection on the basis of stochastic measurement theory. Methods of Psychological Research Online, 1, 65-85.

Eid, M., Courvoisier, D. S., \& Lischetzke, T. (2012). Structural equation modeling of ambulatory assessment data. In M. R. Mehl \& T. S. Conner (Eds.), Handbook of research methods for studying daily life. New York: The Guilford Press.

Eid, M., \& Diener, E. (2004). Global judgments of subjective well-being: Situational variability and longterm stability. Social Indicators Research, 65, 245-277.

Fordyce, M. W. (1977). Development of a program to increase happiness. Journal of Counseling Psychology, 24, 511-521.

Fordyce, M. W. (1983). A program to increase happiness: Further studies. Journal of Counseling Psychology, 30, 483-498.

Geiser, C., Keller, B., Lockhart, G., Eid, M., Koch, T., \& Cole, D. (in press). Distinguishing state variability from trait change in longitudinal data: The role of measurement (non)invariance in latent state-trait analyses. Behavior Research Methods.

Geiser, C., \& Lockhart, G. (2012). A comparison of four approaches to account for method effects in latent state-trait analyses. Psychological Methods, 17, 255.

Gudmundsdottir, D. G. (2013). The impact of economic crisis on happiness. Social Indicators Research, 110, 1083-1101.

Headey, B. W. (2008). The set-point theory of well-being: Negative results and consequent revisions. Social Indicators Research, 85, 389-403.

Headey, B. (2010). The set point theory of well-being has serious flaws: On the eve of a scientific revolution? Social Indicators Research, 97, 7-21.

Headey, B. W., \& Wearing, A. J. (1989). Personality, life events and subjective well-being: Towards a dynamic equilibrium model. Journal of Personality and Social Psychology, 57, 731-739.

Kenny, D. A., \& Zautra, A. (1995). The trait-state-error model for multi-wave data. Journal of Consulting and Clinical Psychology, 63, 52-59.

Kohler, H. P., Behrman, J. R., \& Skytthe, A. (2005). Partner + children = happiness? The effects of partnerships and fertility on well-being. Population and Development Review, 31, 407-445.

Lucas, R. E., Clark, A. E., Georgellis, Y., \& Diener, E. (2004). Unemployment alters the set point for life satisfaction. Psychological Science, 15, 8-13.

Lucas, R. E., \& Donnellan, M. B. (2012). Estimating the reliability of single-item life satisfaction measures: Results from four national panel studies. Social Indicators Research, 105, 323-331. 
Lykken, D., \& Tellegen, A. (1996). Happiness is a stochastic phenomenon. Psychological Science, 7, $186-189$.

Lyubomirsky, S., Dickerhoof, R., Boehm, J. K., \& Sheldon, K. M. (2011). Becoming happier takes both a will and a proper way: An experimental longitudinal intervention to boost well-being. Emotion, 11, 391.

Lyubomirsky, S., \& Lepper, H. S. (1999). A measure of subjective happiness: Preliminary reliability and construct validation. Social Indicators Research, 46, 137-155.

Lyubomirsky, S., Sheldon, K. M., \& Schkade, D. (2005). Pursuing happiness: The architecture of sustainable change. Review of General Psychology, 9, 111-131.

Michalos, A. C. (1985). Multiple discrepancies theory. Social Indicators Research, 16, 347-413.

Michalos, A. C., \& Kahlke, P. M. (2010). Stability and sensitivity in perceived quality of life measures: Some panel results. Social Indicators Research, 98, 403-434.

Mongrain, M., \& Anselmo-Matthews, T. (2012). Do positive psychology exercises work? A replication of Seligman et al. Journal of Clinical Psychology, 68, 382-389.

Mongrain, M., Chin, J. M., \& Shapira, L. B. (2011). Practicing compassion increases happiness and selfesteem. Journal of Happiness Studies, 12, 963-981.

Muthén, L., \& Muthén, B. (2012). Mplus. The comprehensive modelling program for applied researchers: User's guide, 5.

Myers, D., \& Diener, E. (1996). The pursuit of happiness. Scientific American, 274, 54-56.

Odou, N., \& Vella-Brodrick, D. A. (2013). The efficacy of positive psychology interventions to increase well-being and the role of mental imagery ability. Social Indicators Research, 110, 111-129.

Schweizer, K. (2010). Some guidelines concerning the modeling of traits and abilities in test construction. European Journal of Psychological Assessment, 26, 1-2.

Scollon, C. N., \& Diener, E. (2006). Love, work and changes in extraversion and neuroticism over time. Journal of Personality and Social Psychology, 91, 1152-1165.

Seligman, M. E. P., Parks, A. C., \& Steen, T. (2005a). A balance psychology and a full life. In F. Huppert, N. Baylis, \& B. Keverne (Eds.), The science of well-being. Oxford: Oxford University Press.

Seligman, M. E. P., Steen, T. A., Park, N., \& Peterson, Ch. (2005b). Positive psychology progress. Empirical validation of interventions. American Psychologist, 60, 410-421.

Sheldon, K. M., \& Lyubomirsky, S. (2006). Achieving sustainable gains in happiness: Change your actions, not your circumstances. Journal of Happiness Studies, 7, 55-86.

Sin, N. L., \& Lyubomirsky, S. (2009). Enhancing well-being and alleviating depressive symptoms with positive psychology interventions: A practice friendly meta-analysis. Journal of Clinical Psychology, $65,467-487$.

Steyer, R., Schmitt, M., \& Eid, M. (1999). Latent state-trait theory and research in personality and individual differences. European Journal of Personality, 13, 389-408.

Veenhoven, R. (1994). Is happiness a trait? Social Indicators Research, 32, 101-160. 